\title{
Study of phase transitions in cerium in shock-wave experiments
}

\author{
M.V. Zhernokletova ${ }^{\text {a }}$ V.A. Borisenok, V.G. Simakov, V.A. Bragunets, E.E. Shestakov, A.M. Podurets, and M.I. Tkachenko \\ Russian Federal Nuclear Center - All-Russia Scientific and Research Institute of Experimental Physics, Sarov, Russia
}

\begin{abstract}
Cerium has a complex phase diagram that is explained by the presence of structure phase transitions. Planar gauges were used in various combinations in experiments for determination of sound velocity dependence on pressure in cerium by the technique of PVDF gauge. The data of time dependence on pressure profiles with use of $x(t)$ diagrams and the $D(u)$ relation for cerium allowed the definition of the Lagrangian velocity of the unloading wave $C^{\text {Lagr }}$ and the Eulerian velocity $C^{\text {Eul }}$ by taking into account the compression $\sigma$. These results accords with data obtained by using the technique of VISAR and a manganinbased gauge, and calculated pressure dependence of isentropic sound velocity according to the VNIITF EOS. Metallography analysis of post-experimental samples did not find any changes in a phase composition.
\end{abstract}

\section{Introduction}

Cerium is a very convenient material to carry out shock wave studies aimed at deriving a multiphase equation of state and strength characteristics [1].

Analysis of earlier theoretical and experimental researches testifies that cerium properties have been rather completely investigated in the pressure area above $5 \mathrm{GPa}$. There was no actually experimental data in the pressure area lower $5 \mathrm{GPa}$, where, by the theory, extra strong anomaly of thermodynamic characteristics of cerium should be observed. This fact determined the objectives of this work. They are investigation of isomorphic phase $\gamma-\alpha$ transformation in cerium and its abnormal behavior under shock-wave loading in the pressure range up to $3 \mathrm{GPa}$; determination of sound velocity in compressed material; determination of phase transition pressure; metallography of post-experimental samples.

\section{Registration of pressure profiles in cerium}

Cerium samples were loaded under pressures lower than 3.8 GPa with the use of a ballistic facility based on a lightgas gun. Helium was used as a working gas in the gun. The facility is equipped with a laser device intended for shell velocity measurement and an equipment complex intended for the technique of a PVDF gauge.

Samples (targets) with diameter of $52 \mathrm{~mm}$ and with thickness from $2 \mathrm{~mm}$ to $6 \mathrm{~mm}$ were used in the tests. The samples were manufactured using electrolytic cerium having purity of $99.83 \%$. A content of impurities (mass \%) was the following: $\mathrm{La}-0.07 \%, \mathrm{Nd}-0.05 \%, \mathrm{Fe}-0.02 \%$. Density of the material amounted to $6.75 \mathrm{~g} / \mathrm{cm}^{3}$.

Tests were performed with various experimental setups, namely, symmetric impact, asymmetric impact (Figs. 1, 2).

\footnotetext{
${ }^{a}$ Corresponding author: MVZhernokletov@vniief .ru
}

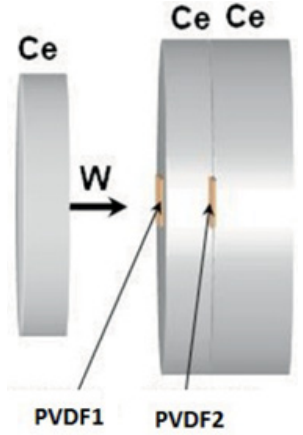

Figure 1. Experimental setup with symmetric impact.

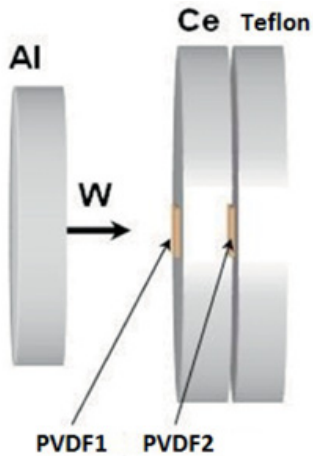

Figure 2. Experimental setup with asymmetric impact.

Velocities of aluminum and cerium impactors were changed from $312 \mathrm{~m} / \mathrm{s}$ to $654 \mathrm{~m} / \mathrm{s}$. It corresponds to loading pressure range in cerium samples $0.81 \mathrm{GPa}$ to $2.28 \mathrm{GPa}$.

Pressure profiles obtained in cerium samples in "gun" and "explosive", test are present in Fig. 3.

Analysis of the $P(t)$ dependence structures shows that a two-wave structure is recorded in cerium (Fig. 3). It consists of the head wave of isentropic compression and the shock wave following after it. Formation of this structure is caused by isomorphic $(\gamma-\alpha)$ phase transition.

This is an Open Access article distributed under the terms of the Creative Commons Attribution License 4.0, which permits unrestricted use, distribution, and reproduction in any medium, provided the original work is properly cited. 


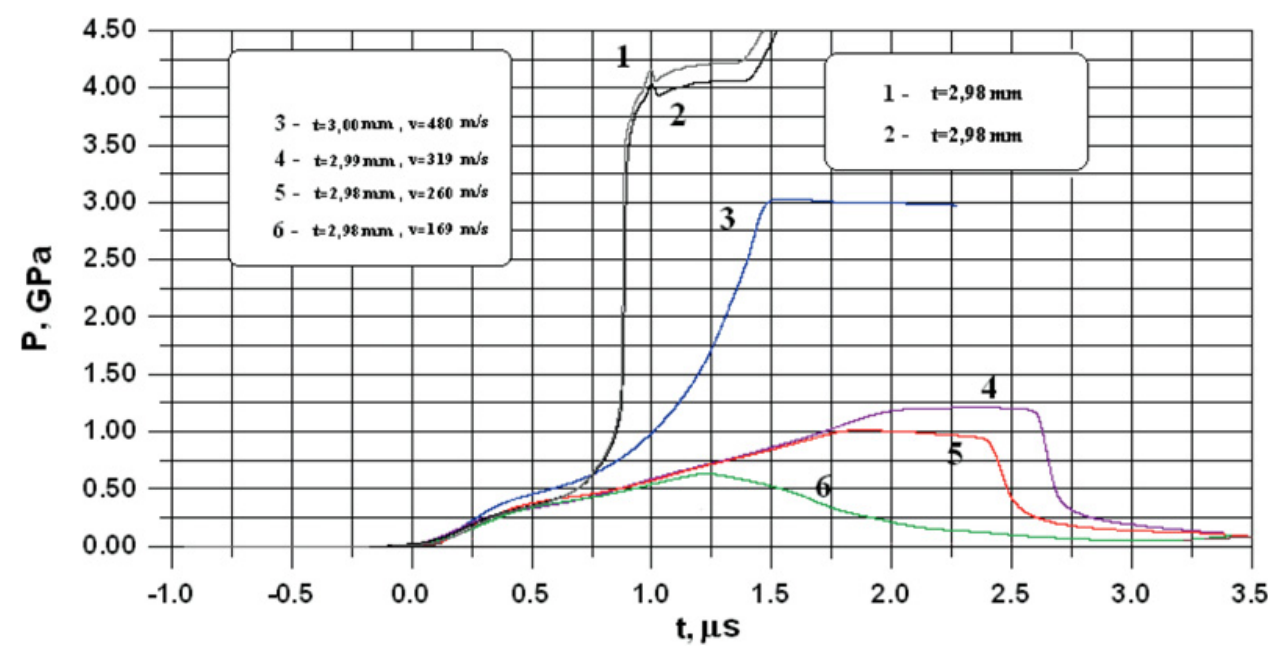

Figure 3. Pressure profiles in cerium under varios loading conditions ranging from (0.8-4.1) GPa.

Table 1. Experimental results. Symmetric impact.

\begin{tabular}{|l|l|l|l|l|l|l|l|}
\hline $\begin{array}{c}\mathrm{W}, \\
\mathrm{m} / \mathrm{s}\end{array}$ & $\begin{array}{c}X \mathrm{Ce}_{i m p}, \\
\mathrm{~mm}\end{array}$ & $\begin{array}{c}X_{\mathrm{Ce}}, \\
\mathrm{mm}\end{array}$ & $\begin{array}{c}U_{\mathrm{Ce}}, \\
\mathrm{km} / \mathrm{s}\end{array}$ & $\begin{array}{c}D_{\mathrm{Ce}}, \\
\mathrm{km} / \mathrm{s}\end{array}$ & $\begin{array}{l}P_{\mathrm{Ce}}, \\
\mathrm{GPa}\end{array}$ & $\begin{array}{l}P_{\mathrm{Ce}}, \\
\mathrm{GPa} \\
\mathrm{phase}\end{array}$ & $\begin{array}{l}C, \\
\mathrm{~km} / \mathrm{s}\end{array}$ \\
\hline 312 & 3.0 & 2.97 & 0.156 & 1.16 & 1.01 & 0.89 & 1.25 \\
\hline 484 & 1.93 & 1.95 & 0.242 & 0.95 & 1.18 & 0.86 & 1.07 \\
\hline 564 & 1.78 & 1.93 & 0.282 & 0.99 & 1.33 & 0.77 & 1.04 \\
\hline
\end{tabular}

Table 2. Experimental results. Asymmetric impact.

\begin{tabular}{|l|l|l|l|l|l|}
\hline $\begin{array}{l}\mathrm{W}, \\
\mathrm{m} / \mathrm{s}\end{array}$ & $\begin{array}{l}\mathrm{XAl}_{\mathrm{imp}}, \\
\mathrm{mm}\end{array}$ & $\begin{array}{l}\mathrm{X}_{\mathrm{Ce}}, \\
\mathrm{mm}\end{array}$ & $\begin{array}{l}\mathrm{D}_{\mathrm{Ce}}, \\
\mathrm{km} / \mathrm{s}\end{array}$ & $\mathrm{P}_{\mathrm{Ce}}, \mathrm{GPa}$ & $\mathrm{C}, \mathrm{km} / \mathrm{s}$ \\
\hline 466 & 3.0 & 3.97 & 0.96 & 1.47 & 0.97 \\
\hline 550 & 3.0 & 3.94 & 1.17 & 1.63 & 0.99 \\
\hline 654 & 3.0 & 3.99 & 1.32 & 1.93 & 1.04 \\
\hline 519 & 4.0 & 1.85 & 1.59 & - & $\begin{array}{l}1.26(1.3) \\
1.93(4.8)\end{array}$ \\
\hline 438 & 4.0 & 1.71 & 1.55 & - & $1.35(1.32)$ \\
\hline
\end{tabular}

It has incomplete character at impactor velocities up to $\mathrm{W}=654 \mathrm{~m} / \mathrm{s}$, which take place in the tests. As a result, the material is a mixture of $\gamma$ and $\alpha$ phases, which determines its anomalous properties. As the impactor velocity grows, shape of the pressure profile in the loading phase approaches its "explosive" analog [2]. Basing on results of all tests, value of the phase transition pressure is $0.83 \pm 0.06 \mathrm{GPa}$.

Decrease in pressure occurs at all $P(t)$ dependences in the zone of constant flow. To all appearances, it can be explained by the occurred isomorphic phase transition. Rarefaction shock wave is formed in the unloading phase.

\section{Sound velocity in compressed cerium}

The information about the sound velocity $C$ is required along with the basic parameters of the equation of state of a substance such as pressure $P$, volume $V$ or density $\rho$, temperature $T$ and entropy $S$. The sound velocity is one of the quantities characterizing a substance behavior under shock compression and subsequent unloading.

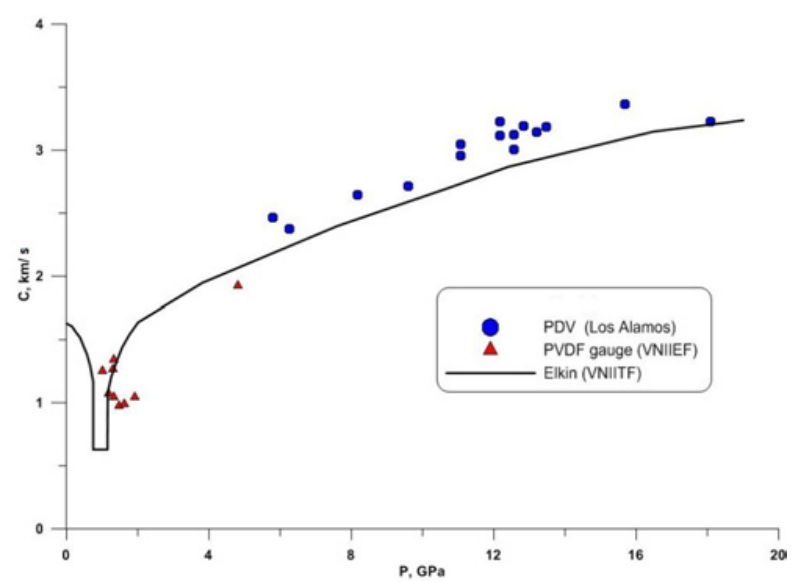

Figure 4. Analytical dependence of bulk sound velocity on pressure at shock-wave loading of cerium [1], data from LANL tests [8] and data from this work.

Planar PVDF gauges were used in various combinations in experiments for determination of pressure dependence on a sound velocity in cerium by the use of the technique of the PVDF gauge.

The data of time dependence on pressure profiles with the use of $x(t)$ diagrams and the $D(u)$ relation for cerium [5] allow the definition of the Lagrangian velocity of the unloading wave $C^{\text {Lagr }}$ and the Eulerian velocity $C^{E u l}$ by taking into account the compressibility $\sigma$. Obtained experimental data are presented in Table 1 and Table 2.

One of the demonstrations of anomalous properties of cerium in the loading phase is the inverse dependence of rarefaction wave velocity on pressure. In [1], results of calculation of bulk sound velocity $C_{\mathrm{B}}$ are presented versus pressure along the curve of isentropic compression of cerium. Experimental confirmation of this phenomenon was obtained in the performed tests (Fig. 4).

Wave velocities $\mathrm{D}$ were determined basing on results of the tests, which had been performed in the regime of symmetric impact. The obtained values were plotted at shock adiabat [3] (Fig. 5). Calculation was accomplished with use of the relation $P=\rho_{0} \cdot D \cdot u$ ( $\rho_{0}$ is the initial density of material; $u \cdot$ is the particle velocity). 


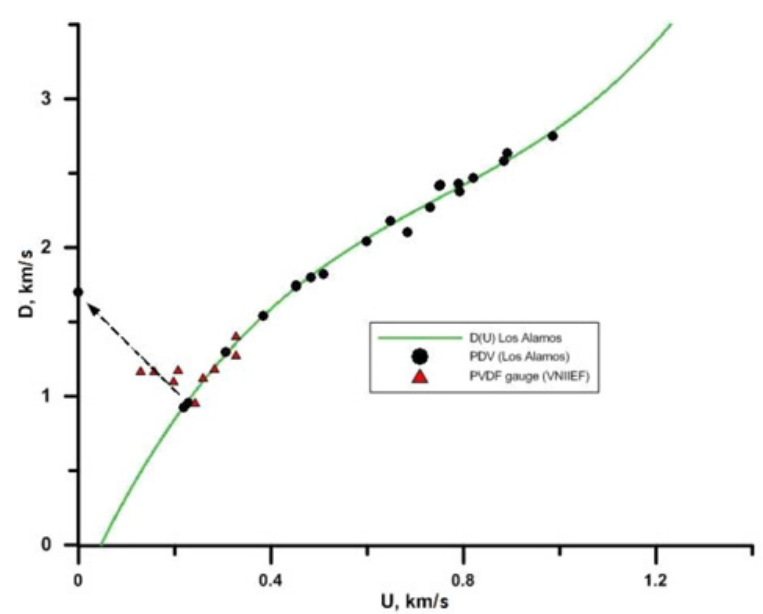

Figure 5. Shock adiabat in D-U coordinates [3] and data from this work.
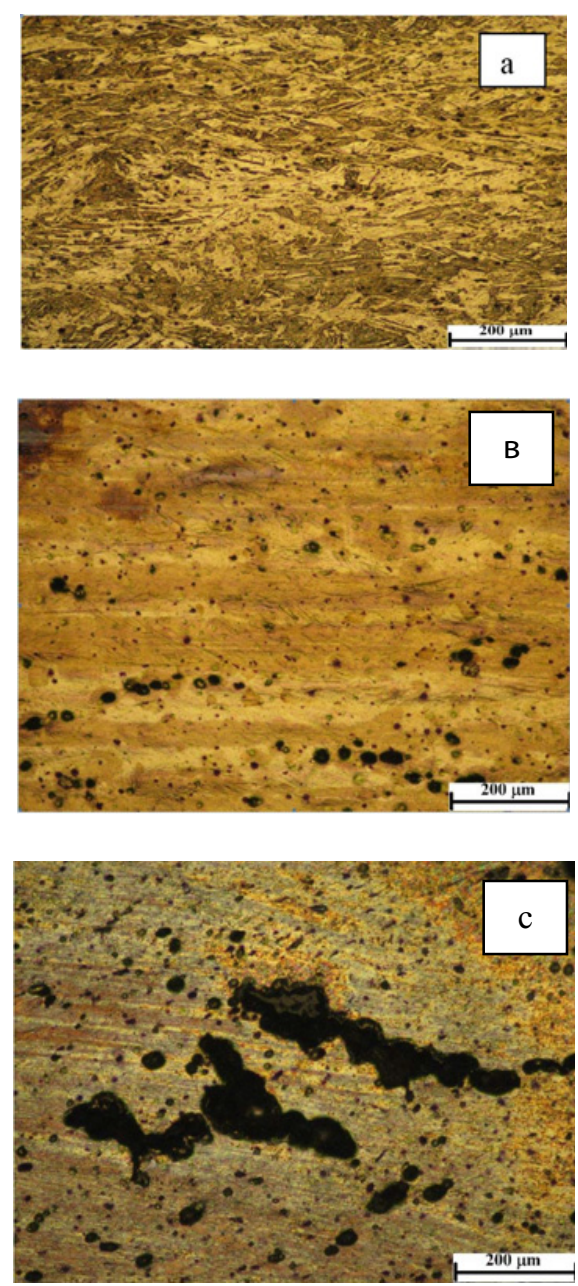

Figure 6. Microstructures of samples in initial state (a); after tests with impactor velocities $\mathrm{W}=550 \mathrm{~m} / \mathrm{s}$ (b) and $\mathrm{W}=654 \mathrm{~m} / \mathrm{s}$ (c).

It follows from the figure that, at $u>0.2 \mathrm{~km} / \mathrm{s}$, the results of this work are well described by the cubic relation, which was obtained in [3]. Significant difference from dependence [3] is observed at lower values of particle velocity. It corresponds to the pressures of $\sim 1 \mathrm{GPa}$.

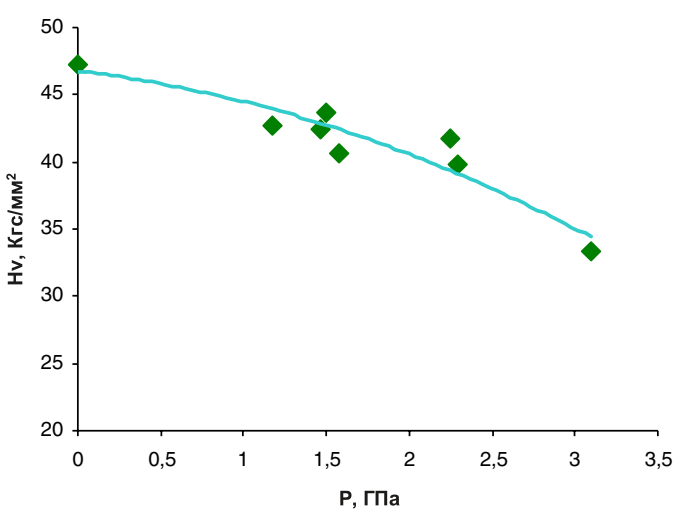

Figure 7. Dependence of microhardness on pressure.

The possible reason is anomalous behavior of cerium at pressures of $\sim 1 \mathrm{GPa}$, which was predicted by the theoretical model [1].

\section{Metallography of post-experimental samples}

In some cases, cerium samples were recovered after shock loading. These samples were investigated by optical metallographic microscope Axiovert $40 \mathrm{MAT}$ at the magnification of $50 \times-500 \times$ in light background and polarized light. Smoothing and polishing of microsection surfaces were mechanically provided by the grindingand-polishing machine "PHOENIX BETA". Microsection etching was chemically accomplished with use of the mixture of nitric acid and glycerin followed by rinsing in ethyl alcohol (Fig. 6).

At the initial stage of formation, damage is accumulation of pores having spherical shapes with the characteristic pore diameters of $20-40 \mu \mathrm{m}$. Microcracks are joined spherical pores.

Measurements of microhardness of a source cerium sample and all samples recovered following tests showed (Fig. 7) its monotone decrease with a rise of a pressure.

\section{Conclusions}

It is demonstrated in the work that incomplete phase $(\gamma-\alpha)$ transition occurs at the mentioned loading pressures. As a result, the substance is a mixture of $\gamma$ and $\alpha$ cerium phases, which determines it anomalous properties. Basing on results of all tests, pressure of the phase transition is $0.83 \pm 0.06 \mathrm{GPa}$. Rarefaction shock wave is formed in the unloading phase. Lagrangian velocities of rarefaction wave were determined basing on the experimental results. Wave velocities $D$ were determined in the tests in the regime of symmetric impact.

An X-ray structural analysis did not find any changes in a phase composition of the tested samples. The $\gamma$-phase is a main phase is $\mathrm{Ce}$ in all the samples, namely in initial samples and samples after tests. The $\gamma$-phase Ce has a face-centered cubic structure. 


\section{References}

[1] M.V. Zhernokletov, A.E. Kovalev, V.V. Komissarov et al. JETPh, 112(2), 212-219 (2011)

[2] V.M. El'kin, E.A. Kozlov, E.V. Kakshina, Yu.S. Moreva, Physics of metals and physical metallurgy. 101(3), 1-10 (2006)

[3] A.R. Kutsar, FMM. 33(5), 1104-1108 (1972)

[4] I.L. Aptekar', E.G. Ponyatovsky, FMM. 25(5), 777786 (1968). II. FMM. 25(6), 1049-1057 (1968)
[5] V.A. Borisenok, V.G. Simakov, V.A. Volgin et al. FGV. 43(4), 121-126 (2007)

[6] B.J. Jensen, F.J. Cherne, J.C. Cooley, M.V. Zhernokletov, A.E. Kovalev, Phys. Rev. B. 81, 214109 (2010)

[7] M.V. Zhernokletov, A.E. Kovalev, V.V. Komissarov, et al. Shock compression of condensed matter (M. Elert, M.D. Furnish, editor, 117-120, 2007) 